\title{
Lalat Predator Coenosia bumilis Meigen (Diptera: Muscidae) pada Pertanaman Kentang: Pola Aktivitas Harian, Pemangsaan, dan Pengaruh Aplikasi Insektisida
}

\author{
Hanuanto $^{\prime \prime}$, D. Hindayana ${ }^{3}$, N. Maryana $^{3}$, dan A. Rauf ${ }^{2}$ \\ Balai Pengkajian Teknologi Pertanian (BPTP) \\ 2Jurusan Hama dan Penyakit Tumbuhan, Fakultas Pertanian - IPB
}

\begin{abstract}
Field and laboratory studies were conducted on potatoes in Pangalengan during April until October 2001, with the objectives to determine the daily activiry pattern of the predatory fly Conosta bomilss Meigen (Diprera: Muscidac), to srudy the behavior of predator as well as level predation, and to evaluate effects of two cultural practices on population of flies. Our research revealed that C. bumilis were more active during morning and afternoon. Predatory flies attacked by capturing the flying preys, and then sucked preys body content. The preys were generally small insects. About $60^{\circ}$ of the preys werc found to be agromyzid flies, Liriony a haidobrnsis (Blanchard) (Diptera: Agromyzidae). In laboratory each predator consumed 23.5 leafminer flies per day. Insecticide application significantly suppressed the predator and at the same time promoted the leafminer population.
\end{abstract}

Key word5: Potato, predator, leafminer Alies, Coenosia bumils, Liriomya baidobrensis.

\section{PENDAHULUAN}

Lalat pengorok daun, Linomyza buidobrensis (Blanchard) (Diptera: Agromyzidae), adalah salah satu hama utama pada pertanaman kentang saat ini. Selain parasitoid, di antara musuh alami L. buidobrensis adalah lalat predator Coenoria bumilis Meigen (Diptera: Muscidae) (Rauf ot al. 2000). C. bumilis pertama kali mendapat perhatian pada saat lalat ini dijumpai sedang memangsa lalat pengorok daun di pertanaman kentang (pengamatan lapangan CahyanaFAO). Pada saat itu tidak banyak hal yang diketahui tentang lalat predator ini, kecuali oleh Karl (1930) yang membuat catatan tentang Muscidac di Jawa,
Sumatera dan Bali berdasarkan koleksi spesimen yang ada di museum.

Di Eropa, sejak 5-10 tahun terakhir, lalat Coenosia telah berhasil dikembangbiakkan secara massal untuk digunakan dalam pengendalian hayat hamahama bunga dan sayuran di rumah kaca (Kuhne 1998). I.arva Coenosia dilaporkan hidup dalam kompos atau bahan organik lainnya dengan memangsa cacing Eisenia spp. (Yahnke and George 1972). Imagonya hidup terestrial dengan memangsa serangga seperti lalat Liriom) $\approx a$, imago kutu kebul, wereng daun, dan berbagai serangga lain yang berukuran kecil (Minkenberg 1990, Kuhne 1998). 
Dipicu oleh berlimpahnya $C$. bumilis di pertanaman kentang (Harwanto et al., 2001), penelitian ini bertujuan memahami pola aktivitas harian, perilaku pemangsaan, jenis mangsa, dan tingkat pemangsaan $C$. bumilis, serta pengaruh aplikasi insektisida terhadap kelimpahan lalat predator.

\section{BAHAN DAN METODE}

Penelitian dilaksanakan di Desa Sukamanah, Kecamatan Pangalengan, Kabupaten Bandung sejak bulan April sampai dengan Oktober 2001. Dalam semua percobaan, varietas kentang yang digunakan adalah Granola. Lntuk mengendalikan serangan patogen, pertanaman diaplikasi dengan fungisida 1-2 kali per minggu. Bila tidak disebutkan secara khusus, selama percobaan berlangsung tidak digunakan insektisida.

\section{Aktivitas Harian}

Penelitian dilaksanakan pada petak pertanaman kentang seluas $500 \mathrm{~m}^{2}$ yang dibagi menjadi empat sub-petak. Aktivitas harian lalat $C$. bumilis dan L. buidobrensis diamati secara in sith dengan menghitung banyaknya lalat $C$. bumilis dan $L$ buidobrensis yang terdapat pada tajuk. Untuk maksud tersebut, pada tiap sub-petak dipilih dua guludan yang masing-masing terdiri dari 15 rumpun. Pengamatan dilakukan pada tiga periode waktu: yaitu pagi (pk. 07.00 - 10.00), siang (pk.11.00 - 14.00), dan sore (pk. $15.00-18.00)$. Pada tiap periode, guludan yang diamati diusahakan berbeda.
Pengamatan berlangsung setiap minggu sejak tanaman berumur 35 hingga 70 HST (Hari Setelah Tanam).

Pengamatan aktivitas harian dilakukan pula dengan perangkap kuning. Perangkap berbentuk silinder (tinggi 18 $\mathrm{cm}$, diameter $8 \mathrm{~cm}$ ), terbuat dari kertas kuning, dan pada seluruh permukaannya dilapisi lem serangga. Pada tiap subpetak dipasang sebanyak 10 perangkap dengan kecinggian $50 \mathrm{~cm}$ dari permukaan tanah. Pengamatan terhadap banyaknya lalat yang tertangkap dilakukan untuk seciap periode (pagi, siang, sore). Pemasangan perangkap berlangsung sebanyak empar kali selama pertumbuhan tanaman.

\section{Perilaku Pemangsaan}

Perilaku pemangsaan diamati secara langsung di lapangan. Pengamatan meliputi proses pemangsaan, frekuensi pemangsaan, dan jenis mangsa. Yang disebut pertama dilakukan dengan menunggui dan mengamati predator sejak menyergap hingga pengisapan mangsa. Frekuensi pemangsaan ditentukan dengan menghitung seluruh predator yang terdapat pada tajuk tanaman contoh dan banyaknya predator dengan mangsa pada alat mulutnya. Pengamatan berlangsung setiap minggu sejak 35 hingga 70 HST. Lama pengamatan pada tiap minggu adalah 2 jam, schingga total lama pengamatan 12 jam. Untuk menentukan jenis mangsa, secara periodik lalat predator dengan mangsa pada mulutnya dikumpulkan dari lapangan. Serangga 
yang menjadi mangsa tadi kemudian dibawa ke laboratorium untuk diidentifikasi.

\section{Tingkat Pemangsaan}

Penentuan tingkat pemangsaan dilakukan dalam kurungan plastik berbentuk silinder yang berukuran diameter 7 $\mathrm{cm}$ dan tinggi $12 \mathrm{~cm}$, dan pada permukaan atasnya ditutupi kain kasa. Ke dalam kurungan dimasukkan sebanyak 30 ekor $L$ buidobrensis dan 1 ekor lalat $C$. bumilis. Setelah 24 jam, banyaknya $L$ buidobrensis yang mati karena dimangsa dihitung dan dicatat. Percobaan diulang sebanyak enam kali. Dalam percobaan ini, lalat $L$ buidobrensis dan C. bumilis diperoleh dengan cara mengumpulkan langsung dari pertanaman kentang yang tidak diaplikasi insektisida.

Penentuan tingkat pemangsaan juga dilakukan pada berbagai kerapatan mangsa, yang dilaksanakan di laboratorium dan di lapangan. Penelitian di laboratorium menggunakan kurungan plastik berukuran diameter $7 \mathrm{~cm}$ dan tinggi $12 \mathrm{~cm}$, sedangkan di lapangan berukuran diameter $40 \mathrm{~cm}$ dan tinggi 70 $\mathrm{cm}$. Masing-masing percobaan diulang 5 dan 6 kali. Ke dalam setiap kurungan dimasukkan lalat $L$ buidobnensis dengan kerapatan 5,10, 15, 20, 25, dan 30 ekor pada percobaan di laboratorium, dan 10 , 20,25 , dan 30 ekor pada percobaan di lapangan. Ke dalam setiap kurungan kemudian dimasukkan 1 ekor lalat $C$. bumilit. Setelah 24 jam banyaknya lalat pengorok daun yang mati karena dimangsa dan yang masih hidup dicatat.

\section{Pengaruh Aplikasi Insektisida}

Pengaruh aplikasi insektisida dikaji dengan membandingkan kelimpahan lalat C. bumilis dan L buidobrensis pada petak tanpa insektisida dan petak petani. Masing-masing petak berukuran $500 \mathrm{~m}^{2}$ dan berjarak sekitar $100 \mathrm{~m}$ satu sama lain. Setiap petak dibagi menjadi empat sub-petak sebagai ulangan. Pada petak petani, insektisida yang digunakan adalah karbosulfan dengan konsentrasi $1,5 \mathrm{cc} / 1$ dan frekuensi aplikasi satu kali per minggu. Kelimpahan lalat $C$. bumilis dan $L$ buidobrensis diamati secara in sitt pada tajuk kentang. Untuk maksud tersebut, pada setiap sub-petak ditentukan 3 unit contoh. Setiap unit contoh terdiri dari 1 $\mathrm{m}$ baris tanaman (3 rumpun) dengan lama pengamatan 10 menit.

\section{Analisis Data}

Sesuai dengan keperluan, analisis ragam diterapkan pada sebagian data untuk menguji perbedaan antar perlakuan. Untuk menilai tingkat signifikansinya dari perbedaan tadi digunakan uji beda nyata jujur (BNJ) pada taraf $5 \%$.

\section{HASIL DAN PEMBAHASAN}

\section{Pola Aktivitas Harian}

Lalat predator dan lalat pengorok daun memiliki pola akcivitas harian yang hampir sama, yaitu keduanya lebih aktif pada pagi dan terutama pada sore hari. 


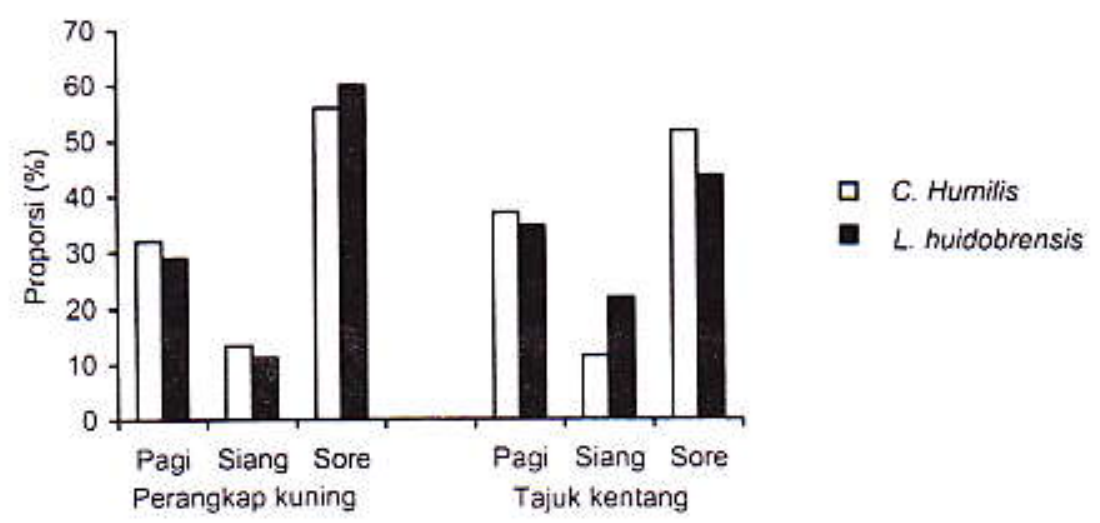

Gambar 1. Proporsi lalat C. humilis dan L. huidobrensis yang tertangkap pada perangkap kuning dan yang hinggap pada tajuk kentang menurut waktu

Hal ini ditunjukkan oleh banyaknya lalat C. bumilis dan $L$ buidobrensis baik yang ditemukan pada tajuk kentang maupun yang tertangkap pada perangkap kuning. Pada pagi hari proporsi lalat C. bumilis atau $L$ buidobrensis yang ditemukan pada tajuk atau yang tertangkap pada perangkap kuning sekitar 2-3 kali lipat lebih banyak dari pada yang tertangkap pada siang hari, sedangkan pada sore hari mencapai 4-5 kali lipat (Gambar 1). Rendahnya aktivitas pada siang hari diduga karena sebagian besar lalat berlindung di tempat yang teduh untuk menghindari terik matahari.

Adanya kesamaan waktu aktivitas antara predator dan mangsanya seperti disebutkan di atas mengisyaratkan potensi yang dimiliki oleh $C$. bumilis dalam menekan perkembangan populasi $L$ buidobrensis. $\mathrm{Hal}$ ini dimungkinkan karena pada keadaan demikian peluang predator menemukan mangsanya lebih tinggi.

\section{Frekuensi dan Perilaku Pemangsaan}

Berdasarkan pengamatan lapangan yang berlangsung selama total 12 jam dijumpai sebanyak 375 ekor lalat $C$. bumilis yang terdapat pada tajuk tanaman contoh dan ajir. Dari jumlah tersebut sebanyak 18 ekor $(4,8 \%)$ sedang melakukan pemangsaan, dengan lebih dari separuhnya dijumpai pada sore hari.

Sebelum melakukan pemangsaan biasanya lalat $C$. bumilis menunggu mangsa dengan bertengger pada daun, ajir, atau subtrat lainnya yang tersedia di pertanaman. Segera setelah melihat mangsa, lalat predator menyergap dan menerkam mangsa yang sedang terbang dengan keenam tungkainya. Lalat predator kemudian hinggap dan segera membunuh dan mengisap mangsa dengan probosisnya. Walaupun mendapat gangguan, seperti pada saat ditangkap dengan botol, predator tetap tidak melepaskan mangsanya. Pada kondisi lapangan, pemangsaan berlangsung sekitar 9-15 menit per mangsa. Pemeriksaan lebih seksama mengungkapkan bahwa 
pengisapan mangsa dilakukan pada bagian abdomen, sedangkan bagian toraks, sayap dan tungkai tampak utuh.

\section{Jenis Mangsa}

Selama penelitian berlangsung berhasil dikumpulkan sebany̧ak 113 ekor lalat $C$. bumilis yang sedang memangsa. Pemeriksaan lebih lanjut di laboratorium mengungkapkan bahwa mangsa $C$. bumilis adalah serangga berukuran kecil. Dari 11 famili yang berhasil diidentifikasi sebagian besar ( 8 famili) termasuk ordo Diptera (Tabel 2). Hal ini sesuai dengan pengamatan Perron et al. (1956) yang mendapatkan lalat (Diptera) sebagai mangsa utama predator $C$. tigrina. Walaupun sulit untuk diidentifikasi sampai jenjang spesies, diperkirakan bahwa sebagian besar dari lalat tadi adalah $L$ buidobrensis. Kelimpahan yang tinggi dari lalat pengorok daun di pertanaman kentang memungkinkannya lebih mudah ditemukan dan lebih dipilih oleh predator.

\section{Tingkat Pemangsaan}

Di laboratorium seekor lalat $C$. bumilis mampu memangsa rata-rata 23,5 ekor lalat pengorok daun selama 24 jam atau sekitar 1 ekor per jam. Pada percobaan ini belum diketahui lama hidup imago predator. Morris and Cloutier (1987) yang meneliti spesies yang lain ( $C$. tigrina) di Kanada melaporkan bahwa lalat betina dapat hidup hingga satu bulan. Kedua peneliti ini menambahkan bahwa setiap ekor lalat predator mampu memangsa sekitar 230 ekor lalat Drosophila selama hidupnya.

Pada kondisi terbuka di lapangan, tingkat pemangsaan ini dipastikan lebih rendah. Namun pada kelimpahan $C$. humilis yang tinggi, seperti pada pertanaman kentang di Pangalengan, diharapkan lalat predator ini dapat memberikan sumbangan dalam penekanan populasi hama L buidobrensis. Kiranya perlu diupayakan cara budidaya tanaman yang dapat mendukung kehidupan lalat C. butmilis.

Percobaan kurungan di laboratorium dan lapangan menunjukkan bahwa

Tabel 2. Berbagai serangga yang menjadi mangsa lalat predator C. humilis pada pertanaman kentang di Pangalengan

\begin{tabular}{llcc}
\hline \hline Ordo & Famili & Jumiah & $\%$ \\
\hline Diptera & Agromyzidae & 68 & 60,18 \\
& Drosophilidae & 7 & 6,19 \\
& Phoridae & 4 & 3,54 \\
& Sciaridae & 4 & 3.54 \\
& Dolichopodidae & 11 & 0,88 \\
& Platystromatidae & 1 & 0,88 \\
Homoptera & Sphaeroceridae & 3 & 2,65 \\
& Chironomidae & 1 & 0,88 \\
Tidak teridentifikasi & Cicadellidae & 3 & 2,65 \\
\hline Total & Psyllidae & 3 & 2,65 \\
& Delphacidae & 15 & 13,27 \\
& & 3 & 2,65 \\
\hline
\end{tabular}


tingkat pemangsaan meningkat dengan bertambahnya kelimpahan mangsa (Tabel 3). Adanya sifat terpaut-kerapatan ini mengisyaratkan ciri perilaku pemangsaan yang baik dari C. bumilis. Analisis yang lebih mendalam tentang pola tanggap fungsional dari predator ini akan dilaporkan tersendiri.

\section{Pengaruh aplikasi insektisida}

Kelimpahan lalat $C$. bumilis dan $L$ buidobrenits selama pertumbuhan tanaman pada petak tanpa insektisida dan petak petani disajikan pada Gambar 2. Kelimpahan lalat predator pada petak petani lebih rendah daripada petak tanpa insektisida; perbedaan yang nyata terjadi pada 42, 61 dan 75 HST (Gambar 2A). Sebaliknya, kelimpahan lalat pengorok daun pada petak petani lebih tinggi dibandingkan pada petak tanpa insektisida; perbedaan yang nyata terjadi pada 68 dan 75 HST (Gambar 2B). Hal ini menunjukkan bahwa aplikasi insektisida scperti yang dilakukan petani selama ini berpengaruh buruk terhadap kehidupan lalat predator. Menurunnya kelimpahan predator, dan mungkin juga musuh alami lainnya, pada petak yang diaplikasi insekrisida diduga mendorong per- kembangan populasi lalat $L$ buidobrensis yang lebih cepat.

Fenomena meningkatnya kelimpahan lalat pengorok daun akibat penggunaan insektisida yang sembarangan dilaporkan pula oleh peneliti lainnya. Johnson et al. (1980) dan Oatman and Kennedy (1976) melaporkan peningkatan populasi $L$ satimae pada pertanaman tomat di California setelah aplikasi insektisida. Kedua peneliti tadi menghubungkan peningkatan kelimpahan lalat pengorok daun dengan terbunuhnya musuh alami khususnya parasitoid.

Secara keseluruhan penelitian yang dilakukan di Pangalengan mengungkapkan tentang potensi yang dimiliki oleh lalat predator C. bumilis sebagai agens pengendalian hayati lalat pengorok daun L buidobrensis. Kchidupan dan kelimpahan lalat predator ini dapat terganggu oleh aplikasi insektisida yang berlebihan, seperti yang ditunjukkan pada lahan petani. Upaya pemanfaatan dan peningkatan kelimpahan C. bumilis pada pertanaman kentang dan sayuran lainnya masih terkendala oleh belum dikuasainya biologi, ekologi, dan teknik pembiakan massal dari predator ini.

Tabel 3. Rataan banyaknya lalat $L$. huidobrensis yang dimangsa lalat $C$. humisis pada berbagai kerapatan mangsa (percobaan kurungan di laboratorium dan lapangan).

\begin{tabular}{ccc}
\hline \hline $\begin{array}{l}\text { Banyaknya lalat } \\
\text { L. huidobrensis }\end{array}$ & Rataan banyaknya lalat $L$. huidobrensis yang dimangsa $(x \pm S D)$ \\
\cline { 2 - 3 } & Laboratorium & Lapangan \\
\hline 5 & $3,8 \pm 1,64$ & tidak ada data \\
10 & $6,2 \pm 3,03$ & $5,17 \pm 1,94$ \\
15 & $8,8 \pm 5,07$ & tidak ada data \\
20 & $10 \pm 5,15$ & $8,50 \pm 1,38$ \\
25 & $19,2 \pm 6,98$ & $13,67 \pm 3,50$ \\
30 & $21,4 \pm 7,13$ & $17,33 \pm 5,57$ \\
\hline
\end{tabular}



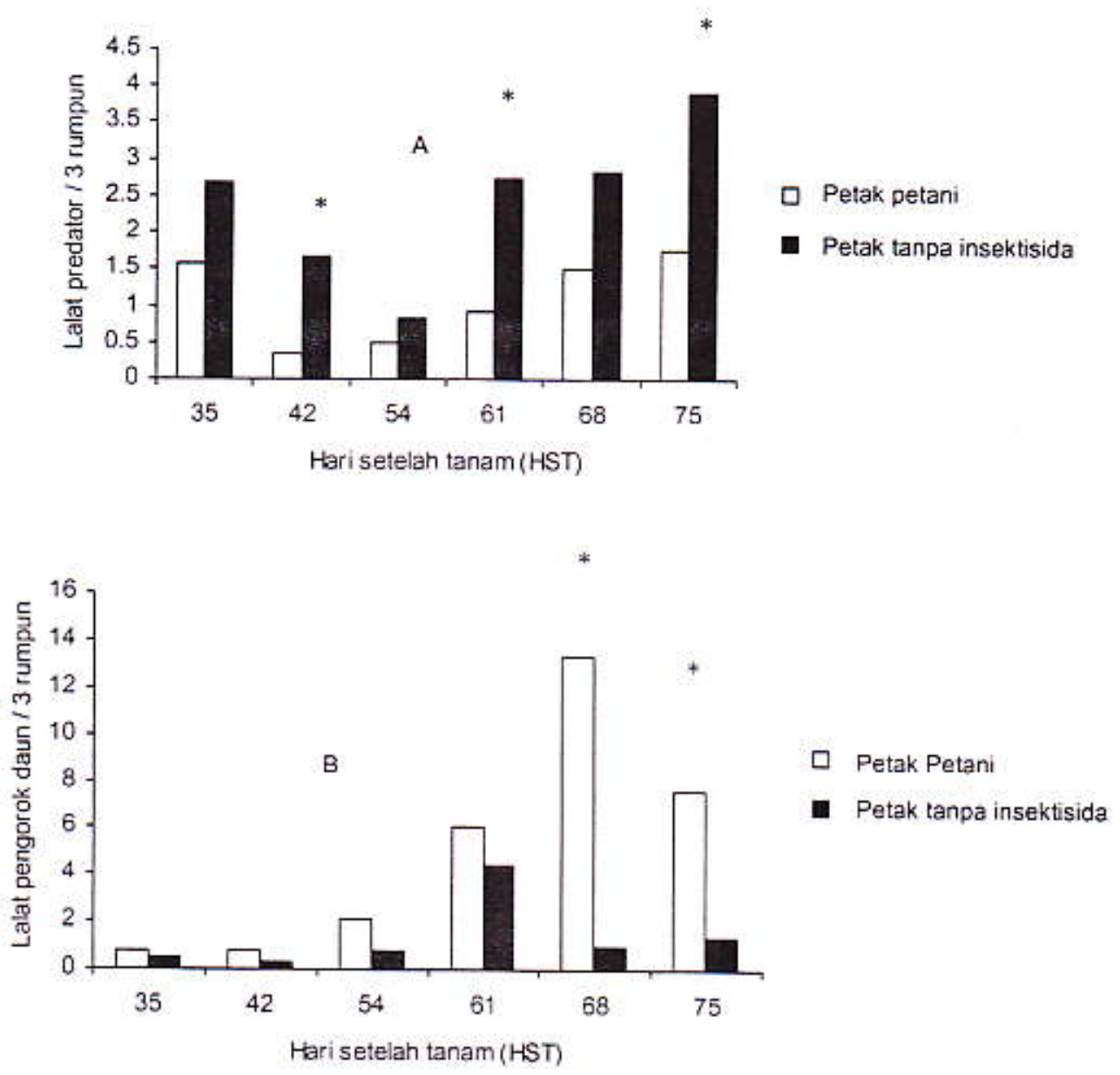

Gambar 2. Kelimpahan lalat predator (A) dan lalat pengorok daun (B) pada lahan tanpa insektisida dan lahan petani ("berbeda nyata pada taraf $5 \%$ ).

\section{KESIMPULAN}

Lalat predator C. bumilis memiliki potensi sebagai agens pengendalian hayati. Potensi ini ditunjukkan oleh kelimpahannya yang tinggi dengan mangsa utama L buidobrensis, kesamaan pola aktivitas hariannya dengan mangsa utama, serta sifatnya yang terpaut kerapatan dengan mangsa. Penggunaan insektisida seperti yang dipraktekkan oleh petani selama ini berpengaruh buruk terhadap kelimpahan predator. Pemanfaatan lalat C. bumilis dalam PHT kentang masih memerlukan penelitian lanjutan terutama tentang biologi dan ekologinya.

\section{DAFTAR PUSTAKA}

Harwanto, Rauf A, Maryana X, dan Hindayana D. 2001. Studi pendahuluan kelimpahan dan potensi Coenosia humilis Meigen (Diptera: Anthomvidae): Predator lalat pengorok daun dalam Sukartana $P$. Prasadja I, Arifin X, Wikardi E.t, dan Kaomini, Soesilawati (Eds.). Pengelolaan serangga yang bijaksana menuju optimasi produksi. Prosiding Seminar Nasional III PEI Cabang Bogor. 153-158.

Johnson MN, Oatman ER, and Wyman J.A. 1980. Effects of insecticides on populations of the vegerable leafminer and 
associated parasites on summer pole tomatoes. J Econ Entomol 73:61-66.

Karl VO. 1930. Muscidae (Anthomyidae) von Java, Sumatera und Bali. Arrchip fur Hydrobiologie. Suppl Bd VIII S:111-114.

Kuhne S. 1998. Open rearing of generalist predators: A strategy for improvement of biological pest control in greenhouses. Phytoparasitica, 26:277-281.

Minkenberg OPJM. 1990. The leafminer Lirions ra trijolii and Lirions $\gamma^{a}$ broninas, their parasitoids and host plants: a review. In Seasonal inoculative biological control. p. 23-59.

Morns DE, and Cloutier C. 1987. Biology of the predatory fly Coenosia tigrina (Fab.) (Diptera: Anthomvidae): Reproduction, development, and larval fecding on earthworms in the laborarory. Can. Entomol. 119:381-393.

Oatman ER, and Kennedy GG. 1976. Methomỵ] induced ourbreak of Linomyza sativae on tomatoes. J Econ Entomol 69:667-668.

Perron JP, LeRoux EJ, and LaFrance J. 1956. Notes on Coenosia tigrina (F.) (Diptera: Anthomyidae) mainly on habits and rearing. Can. Entomol. 88:608-611.

Rauf A, Shepard BM, and Johnson MN. 2000. Leafminers in vegetables, omamental plants and weeds in Indonesia: surveys of host crops, species composition and parasitoids. Internat J Pest Management 46:257-266.

Yahnke WE, and George 1A. 1972. Earthworms as prey for lanae of Coenosia tigrina. I Econ Entomol 65:1478-1479. 